\title{
Presenting a Typology of Efficiency and Their Plausible Measurement into Healthcare Systems: A Global View
}

\author{
Ali Rawabdeh*, Ali Ahamd Awad Rawabdeh \\ Health Services Management Master's Program, Faculty of Economics and Administrative Sciences, Yarmouk University, Irbid, \\ Jordan
}

Received August 5, 2021; Revised August 28, 2021; Accepted October 7, 2021

\begin{abstract}
Cite This Paper in the following Citation Styles
(a): [1] Ali Rawabdeh, Ali Ahamd Awad Rawabdeh, "Presenting a Typology of Efficiency and Their Plausible Measurement into Healthcare Systems: A Global View, "Universal Journal of Public Health, Vol. 9, No. 5, pp. 276 - 286, 2021. DOI: 10.13189/ujph.2021.090510.
\end{abstract}

(b): Ali Rawabdeh, Ali Ahamd Awad Rawabdeh (2021). Presenting a Typology of Efficiency and Their Plausible Measurement into Healthcare Systems: A Global View. Universal Journal of Public Health, 9(5), 276 - 286. DOI: 10.13189/ujph.2021.090510.

Copyright $\odot 2021$ by authors, all rights reserved. Authors agree that this article remains permanently open access under the terms of the Creative Commons Attribution License 4.0 International License

\begin{abstract}
Health care systems around the globe suffered from inefficient delivery and financing systems. This paper aims to introduce and measure insights into the typology of efficiency of the health care system in Jordan and the like to improve and enhance the healthcare outcomes (Health Status). The researcher screened the typology and likely measures of efficiency in the health care industry in the published materials and characterized potential measures accordingly. In addition to that, the researcher consulted highly experienced colleague experts in different fields to generate and abstract information. This descriptive and analytical study utilized descriptive statistics to evaluate the six types of efficiency in the health sector and primarily employed a comparison between the neighborhood and universal figures of three epochs (the 1990s to 2020) based on worldwide authorized database records (World Bank). The 25\% wastage of health expenditures in Jordan is compared favorably with the worldwide trend of $20-40 \%$. Progressing efficiency within the health system can reduce the rising cost; provide equitable services to the penniless. Hence, prioritizing among available choices (70\% curative and 30\% preventive) ought to be based on health problems, social and financial-related components. Unequivocally, addressing priority setting is imperative to make more efficient strategies of allocation for scarce productive health resources. Despite the remarkable productive, technical, social with minimal vertical and horizontal efficiency capabilities of the Jordanian health care delivery
\end{abstract}

and financing systems founded, a thoroughly enforced reform strategy can way better fit to attain the national key objective (health for all Jordanians in 2025). There were no majestic studies or other implications coupled with a lack of information to recognize the importance of efficiency in health systems encourage in selectivity and prioritization of health services delivery conveyance to the total mass in an efficient manner. In this manner, this paper came to recognize essentially pertinent six sorts of efficiency that could be utilized and measured in health systems, suggesting all over the maximization of outputs for a given level of inputs indicators. Subsequently, presenting efficiency into healthcare systems is profoundly approved because it can offer room for advancing equity and esteem in healthcare.

Keywords Efficiency, Health Care System, Efficacy Measurement, Equity, Effectiveness

\section{Introduction}

Literary works appeared that in the late of the twentieth century the universal health expenditure has been growing faster than countries income. This growth can be credited to demand and supply-side components (i.e. aged population and medical revolution). Further to that, there's sufficient proof of inescapable wastefulness in the 
conversion of health inputs into outputs, triggering financial loss and increase health expenditures.

This paper aims to introduce and measure the typology efficiency of the health care system in Jordan and the like to improve and enhance the healthcare outcomes.

The application of typology of efficiency in health care systems is highly inspiring, while raising both hypothetical and common sense issues i.e., outcomes feasible indicators for measurements.

The connection between health inputs and outputs (outcomes or health status) is so complex and polygonal. Inputs and outputs vary in their measured dimensions, such as on quantity and quality, while health status is as a rule influenced by components beyond the control of the health system i.e., dynamic environment (micro and macro) The inaccessible information in the health system confines the use of diverse types of efficiency and thereby making their assessment thought-provoking. In spite of the pragmatic troubles in applying efficiency concepts to health systems, there is significant evidence on the omnipresence of inefficiency in the health sector. On the contrary, if resources are utilized efficiently, the average life of expectancy might be expanded by two years; and, while increasing efficiency may lead to sparing of a significant sum of assets, containing fast increment of cost (expenditure), improving quality and coverage of health services, etc.

The aim is to assess whether efficiency scores are energetic in health systems, acknowledged and applied so as to improve health status, achieve economic gains, shrink cost escalation in health care, improve access, invest in less cost effective strategies arrange to attain health for all in 2025. This descriptive and analytical study utilized descriptive statistics to evaluate the six types of efficiency in the health sector, and primarily employs a comparison between the neighbourhood and universal figures of three epochs of time (the 1990s to 2020) based on worldwide authorized database records (World Bank).

This paper realizes and acknowledges essentially appropriate six types of efficiency that might be utilized and measured in health systems, proposing all over the maximization of outputs for a given level of inputs or minimization of inputs for a given level of outputs which will be interpreted into health outcome and/or health status indicators i.e., life expectancy, IMR, MMR, CDR; while inputs may incorporate expenditure use on health care per se, physical inputs and environmental factors.

This paper finds around $25 \%$ of health expenditures in Jordan to be a squander of scares productive resources which are comparable to the worldwide wastage trend of $20-40 \%$. In addition to that, Jordan spends $70 \%$ of the net share from the GNP on curative services and $30 \%$ on preventive services. This implies that Jordan spends on less cost-effective measures.

Despite the remarkable productive, technical, social with minimal vertical and horizontal efficiency capabilities of the Jordanian health care delivery and financing systems founded, a thoroughly enforced reform strategy can way better fit to achieve the main objective of the study.

\subsection{Problem}

Health systems around the globe are battling with rising costs due to an increase in demand for health care that is maybe due to the annual growth rate of the population; technology; increases in the cost of inputs to produce output; and, initiation of national health insurance systems.

The Jordanian health care system is similar to countries of the need of financial maintainability of most healthcare frameworks to back to the improvement of control within the health sectors.

Indeed, despite the difficulty in health facilities to function within the most efficient and effective manners; efficiency ought to be taken care of carefully since it can progress and hinder health outcomes.

Undoubtedly, in spite of the trouble in health facilities to operate within the foremost efficient and effective conduct; efficiency got to be taken care of carefully since it can advance and prevent health outcomes.

\subsection{Aims and Objectives}

Since the efficiency of the health care system can offer room for ranking equity, quality, and access to healthcare, the aim of this article came to point the common typology of efficiency to improve and enhance the healthcare outcomes.

\section{Materials \& Methods}

The researcher screened the typology and likely measures of efficiency in the health care industry in the published materials and characterized potential measures accordingly. Databases were consulted for the last two decades by using specific terms i.e., efficiency, effectiveness, productivity, and economic gains in health-related fields for published articles. In addition to that, the researcher consulted highly experienced colleagues to generate and abstract information that they develop to measure their efficiency in certain projects. As the input and output the clearly measures of efficiency, they have been defined and specified as the number of 8Ms (money, materials, manpower, management, methods, means, manufactures, and milieu) (input) used to produce the output, and the type of health product respectively (output) (health services i.e., outpatient visits, inpatient discharged, the average length of stay, the average cost per patient per day, and health outcomes, i.e., morbidity, 
mortality, disability rates/ratios.). The measures of efficiency were also specified by biostatistics based on the specified variables of the study

\subsection{Efficiency in Health Care}

There are two viewpoints of efficacy in health care. Efficiency in the utilization of services is communicated over demand and supply sides limitations. While, efficiency in the production of services is the scale of production; blend of inputs; getting the correct scale and mix requires $[1,2]$.

\subsection{Aspects of Efficacy}

Productive efficiency: it can be accomplished in the off chance that the health facility produces its amount of output with the least conceivable amount of inputs. It is measured as the proportion of actual output to effective capacity. It is called sometimes technological efficiency and/or (technical efficiency) [3, 4].

Technical efficiency: is the generation of a given quantity of output with the slightest cost combination (the least esteem of inputs). It suggests the productively efficient strategies of production; the cheapest method has been chosen. In the event that the input cost changes the technically efficient method of production may change [4].

Allocative Efficiency: It happens when utilization the extra output - coming about from productive and technical efficiency - to make a few individuals better off without making anyone else worse off. If resources are being used to supply ineffective treatment, at that point the output can be expanded by utilizing the resources to supply viable treatment instep, without anyone being worse off [4].

Social efficiency: It considers the dissemination of output (reallocation of resources to make one person better off without making at least one other person worse off). In a society with a very unequal distribution of income, it isn't conceivable to move forward the conditions of the poor without expanding the tax assessment of the wealthy (equity). Social efficiency occurs if the total benefit to the gainers exceeds the total loss of the losers $[4,5]$.

Horizontal efficiency: The proportion of those needing the services who actually receive them.

Vertical efficiency: The proportion of services that go to those who need them rather than to those who don't [6].

\subsection{Efficiency in Health Care System}

Producing a greater amount of output with the same amount of inputs is the essence of efficiency in health care. Health care systems need to be efficient as conceivable. The pundits here would be over profoundly efficient by maximizing the number of scheduled treatments at the expanse of what may be very expensive treatments $[7,8]$. The health services organization managers are more likely to focus on cost efficiency; trying to find ways of reducing the cost without reducing activity levels, or increasing activity levels without significantly increasing costs [7].

Quantifying of capacity utilization ought to be measured to see how to plan the accessible assets are being utilized. There are a variety of measures, but the article constrained them to utilize the: Average Length of Stay (ALOS) is the average number of days spent in the hospital; Occupancy Rate (OR): The average percentage of the available capacity occupied per day; and, Throughput Rate (TR): the number of patients treated per units of capacity (i.e. per bed) in the time period under consideration) $[4,8]$.

\subsection{Efficiency Measurement}

Efficiency is the ratio of the output to the inputs of any framework. An efficient framework or is one that accomplishes higher levels of performance (outcome: health status, output: health services utilization) relative to the inputs (8Ms: manpower, money, materials, management, methods, means, manufactures, milieu) consumed $[9,10]$.

Efficiency measures must too unequivocally recognize the inputs that are utilized to produce output. Inputs can be measured as checks by sort (inpatient days, professionals working hours) or they can be monetized (financial budgeted requirements assigned to each unit). These can be stated as physical inputs or financial inputs $[1,9,11]$.

\section{Results}

Efficiency refers to the relationship between resource inputs and the resultant outputs. A health provider or system is said to be 'efficient' if it attains its objectives at the least possible cost. Effectiveness and efficiency in delivering health care services are crucial indicators to the attainment of health goals at the country level as well as health for all strategy in the year 2025. There has been a significant enlargement in all categories of medical and allied health personnel aside from nursing since 1994. The number of doctors had increased by $38 \%$ from 1.6 in the 1990 s to 28.6 per 10000 populations today. Also, the number of pharmacists is quite doubled from 0.8 to 17.8 pharmacists per 10,00, Whereas the number of nurses has remittent by $7 \%$ since the 1990 s, 32 nurses per 10,000 might have a negative consequence on the standard of care provided as well as on costs. There are 117 hospitals and quite 15003 beds within the Hashemite Kingdom of Jordan, 2020. The number of beds increased from 13349 
in 2016 to 15003 in 2019. This suggests that there was the population/ bed ratio of $18 / 10000$ in 2016 was declined to $14 / 10000$ in 2019 [12].

\subsection{Measurement of Productive and Technical Efficiency}

There are two types of efficiency analysis strategies. The parametric strategy is advancing the stochastic frontier production function and which is inclosing the data envelopment analysis [10,11]. This paper has used the latter whereas a few methodological difficulties can arise due to lack of data.

The productive efficiency may even be assessed by the relation between the output and inputs. This article accepts the ratio-based measures of output and input. The output which will be represented by the outcomes (Health Status) was measured in terms of epidemiological perspective as mortality, morbidity, and disability indicators. Due to the need of information and time, the health status indicator specified and limited to the foremost important indicator of Infant Mortality Rate (IMR), Maternal Mortality Rate (MMR), Crude Death Rate (CDR), and, Life Expectancy at Birth. Whereby, the input indicators were acknowledged to be represented by the esteem of $(8 \mathrm{Ms})$ which will be observed in terms of total health expenditures $[11,13]$.

The other way of observing the output is to accept that they might be indicated and constrained to hospital discharges, procedures, physician visits, and/or quality of services ${ }^{10}$. As this information not available in the Jordanian health care system as a whole, the article centred on outcomes as of critical measure of productive efficiency and others.

On the other hand, the inputs indicator could be observed in terms of cost of inputs, and/or cost of physical resources e.g., Relative Value Units (RVUs) for a procedure, e.g., cost per patient per day, cost per physician visit, etc. Also, due to the need for information, the article accepted the total health expenditures as a sufficient measure of inputs [7, 13, 14].

With reference to output (outcomes-health status) accepted measures for the Jordanian health care system, the life expectancy at birth has been increased in a comparative drift of the neighbouring countries in almost five degrees of moderate pace from 69.8 years in the 1990s to 74.5 Years in 2019 (see Table 1). It looks better than the Arab world nations 71.9Y; the Middle East \& North Africa countries 64.2Y, and the world average 72.74Y. It compares positively with East Asia \& Pacific 57.4; and, least developed countries 75.3Y. Whereas in terms of Infant Mortality Rate, Jordan demonstrates a profoundly significant diminish rate from 29.9/1000 live births in 1990 to 13.4/1000 live births in 2019 as (see Table 2). It appears to be better than the Arab world 26.1, middle east and northern African countries 18.1 and the world average of 28.2/1000 live births. In terms of Maternal Mortality Rate, Jordan witnessed a sharp decrease from 110/100,000 live births in 1990 to 46/100,000 live births in 2019 (see Table 3), It is way better than the Arab World 149, Middle-East and Northern African countries 57, and the world average 211. And lastly, as in table (4), Jordan scored an impressive diminish in Crude Death Rate from 5.06/1000 in 1990 population to 3.889/1000 population in 2019 (see Table 4). It appears to be way better than all the compared zones locally and internationally, except Kuwait 2.8, Qatar 1.2, and Oman 2.4.

With the reference of inputs that represented by the esteem of (8Ms) which will be observed in terms of total health expenditures (or cost of input/8ms), Jordan observed a fluctuated mild decrease of total health expenditures of $9.6 \%$ of GDP in 1990 to $7.7 \%$ of GDP in 2018 (see Table 5). It looks like in the current circumstances superior to all of the neighbouring nations and the international field, except the world average 9.84\%; Euro area 20.13\%; European Union 9.5\%; and, OECD members $12.45 \%$ [7]. This deterioration of spending does not influence that area development in the health status as above, this would lead to a productively efficient health care system in Jordan. On the other hand, the technical efficiency (economic efficiency) which is measures by the generation of a given quantity of output with the least cost combination (the minimum value of inputs) $[10,13]$, the above economic evaluations by utilizing regional and international benchmarking strategy shows that the reduction in the health spending in Jordan does not influence the quality of services that surrender and represented by favourable outcomes proves the technically efficient health care system. 
Table 1. Life Expectancy at Birth (total, Male and Female)/Years

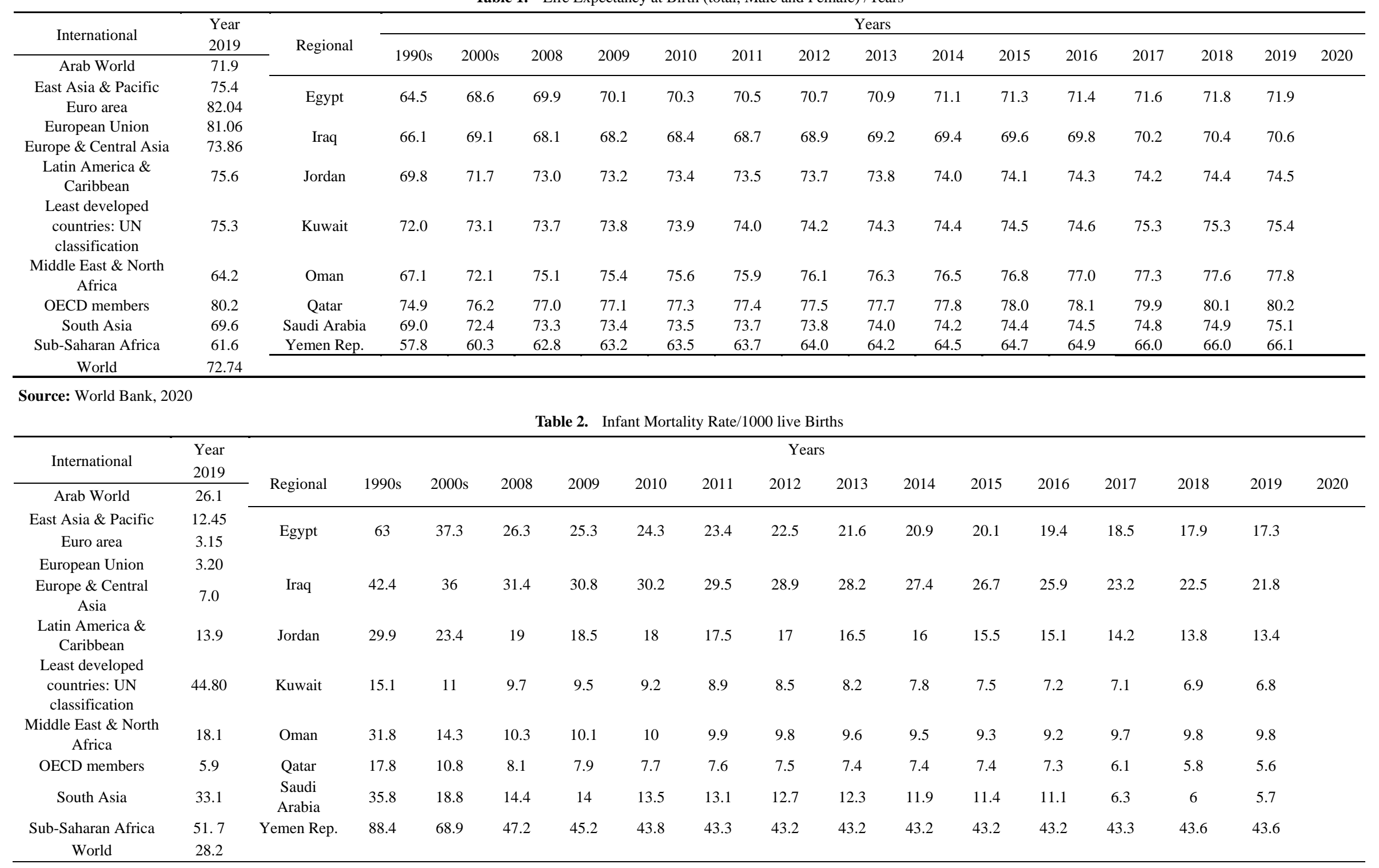

Source: World Bank, 2020 
Table 3. Maternal Mortality Ratio (Estimate per 100,000 live births)

\begin{tabular}{|c|c|c|c|c|c|c|c|c|c|c|c|c|c|c|c|c|c|}
\hline \multirow{2}{*}{ International } & \multirow{2}{*}{$\begin{array}{l}\text { Year } \\
2019 \\
\end{array}$} & \multicolumn{16}{|c|}{ Years } \\
\hline & & \multirow[b]{2}{*}{ Regional } & \multirow[b]{2}{*}{$1990 \mathrm{~s}$} & \multirow[b]{2}{*}{$2000 \mathrm{~s}$} & \multirow[b]{2}{*}{2008} & \multirow[b]{2}{*}{2009} & \multirow[b]{2}{*}{2010} & \multirow[b]{2}{*}{2011} & \multirow[b]{2}{*}{2012} & \multirow[b]{2}{*}{2013} & \multirow[b]{2}{*}{2014} & \multirow[b]{2}{*}{2015} & \multirow[b]{2}{*}{2016} & \multirow[b]{2}{*}{2017} & \multirow[b]{2}{*}{2018} & \multirow[b]{2}{*}{2019} & \multirow[b]{2}{*}{2020} \\
\hline Arab World & 149 & & & & & & & & & & & & & & & & \\
\hline $\begin{array}{c}\text { East Asia \& Pacific } \\
\text { Euro area }\end{array}$ & $\begin{array}{c}69 \\
5\end{array}$ & Egypt & 106 & 63 & 45 & 43 & 40 & 39 & 37 & 35 & 34 & 33 & 38 & 37 & 106 & 63 & \\
\hline European Union & 6 & & & & & & & & & & & & & & & & \\
\hline $\begin{array}{c}\text { Europe \& Central } \\
\text { Asia }\end{array}$ & 13 & Iraq & 107 & 63 & 90 & 75 & 70 & 67 & 66 & 75 & 92 & 83 & 78 & 79 & 107 & 63 & \\
\hline $\begin{array}{l}\text { Latin America \& } \\
\text { Caribbean }\end{array}$ & 74 & Jordan & 110 & 77 & 55 & 54 & 53 & 52 & 52 & 51 & 49 & 48 & 47 & 46 & 110 & 77 & \\
\hline $\begin{array}{l}\text { Least developed } \\
\text { countries: UN } \\
\text { classification }\end{array}$ & 415 & Kuwait & 7 & 10 & 10 & 10 & 10 & 10 & 11 & 11 & 11 & 11 & 12 & 12 & 7 & 10 & \\
\hline $\begin{array}{c}\text { Middle East \& North } \\
\text { Africa }\end{array}$ & 57 & Oman & 30 & 20 & 18 & 18 & 18 & 18 & 18 & 18 & 18 & 17 & 19 & 19 & 30 & 20 & \\
\hline OECD members & 18 & Qatar & 29 & 24 & 17 & 17 & 16 & 15 & 14 & 13 & 13 & 13 & 9 & 9 & 29 & 24 & \\
\hline South Asia & 163 & $\begin{array}{l}\text { Saudi } \\
\text { Arabia }\end{array}$ & 46 & 23 & 20 & 20 & 19 & 18 & 18 & 17 & 17 & 17 & 17 & 17 & 46 & 23 & \\
\hline Sub-Saharan Africa & 534 & Yemen Rep. & 547 & 440 & 208 & 200 & 192 & 187 & 184 & 175 & 174 & 169 & 165 & 164 & 547 & 440 & \\
\hline World & 211 & & & & & & & & & & & & & & & & \\
\hline
\end{tabular}

Source: World Bank, 2020

Table 4. Crude Death Rate/1000 population

\begin{tabular}{|c|c|c|c|c|c|c|c|c|c|c|c|c|c|c|c|c|c|}
\hline \multirow{2}{*}{ International } & \multirow{2}{*}{$\begin{array}{l}\text { Year } \\
2019 \\
5.35\end{array}$} & \multicolumn{16}{|c|}{ Years } \\
\hline & & Regional & $1990 \mathrm{~s}$ & $2000 \mathrm{~s}$ & 2008 & 2009 & 2010 & 2011 & 2012 & 2013 & 2014 & 2015 & 2016 & 2017 & 2018 & 2019 & 2020 \\
\hline $\begin{array}{l}\text { East Asia \& } \\
\text { Pacific }\end{array}$ & 6.96 & Egypt & 8.406 & 6.487 & 6.273 & 6.241 & 6.206 & 6.166 & 6.121 & 6.071 & 6.017 & 5.963 & 5.909 & 5.863 & 5.817 & 5.778 & \\
\hline $\begin{array}{c}\text { Euro area } \\
\text { European Union }\end{array}$ & $\begin{array}{l}10.03 \\
10.39\end{array}$ & & & & & & & & & & & & & & & & \\
\hline $\begin{array}{c}\text { Europe \& Central } \\
\text { Asia }\end{array}$ & 10.07 & Iraq & 6.996 & 5.575 & 5.7 & 5.652 & 5.578 & 5.484 & 5.381 & 5.279 & 5.183 & 5.096 & 5.02 & 4.826 & 4.776 & 4.736 & \\
\hline $\begin{array}{l}\text { Latin America \& } \\
\text { Caribbean }\end{array}$ & 6.38 & Jordan & 5.064 & 4.126 & 3.889 & 3.878 & 3.867 & 3.857 & 3.848 & 3.84 & 3.834 & 3.829 & 3.828 & 3.843 & 3.864 & 3.889 & \\
\hline $\begin{array}{l}\text { Least developed } \\
\text { countries: UN } \\
\text { classification }\end{array}$ & 7.17 & Kuwait & 2.561 & 2.527 & 2.54 & 2.541 & 2.545 & 2.554 & 2.571 & 2.597 & 2.633 & 2.681 & 2.739 & 2.601 & 2.696 & 2.802 & \\
\hline $\begin{array}{c}\text { Middle East \& } \\
\text { North Africa }\end{array}$ & 4.89 & Oman & 5.483 & 3.518 & 2.895 & 2.845 & 2.799 & 2.754 & 2.709 & 2.663 & 2.618 & 2.574 & 2.533 & 2.462 & 2.436 & 2.422 & \\
\hline OECD members & 8.56 & Qatar & 2.166 & 2.018 & 1.61 & 1.568 & 1.534 & 1.51 & 1.496 & 1.491 & 1.495 & 1.509 & 1.531 & 1.169 & 1.202 & 1.244 & \\
\hline South Asia & 7.02 & Saudi Arabia & 4.935 & 3.737 & 3.597 & 3.587 & 3.572 & 3.557 & 3.543 & 3.534 & 3.533 & 3.54 & 3.557 & 3.446 & 3.472 & 3.505 & \\
\hline $\begin{array}{l}\text { Sub-Saharan } \\
\text { Africa }\end{array}$ & 8.41 & Yemen Rep. & 11.472 & 9.09 & 7.4 & 7.234 & 7.088 & 6.958 & 6.842 & 6.735 & 6.636 & 6.543 & 6.456 & 5.978 & 5.983 & 5.983 & \\
\hline
\end{tabular}

Source: World Bank, 2020 
Table 5. Health Expenditures (\%of GDP)

\begin{tabular}{|c|c|c|c|c|c|c|c|c|c|c|c|c|c|c|c|c|c|}
\hline \multirow{2}{*}{ International } & \multirow{2}{*}{$\begin{array}{l}\text { Year } \\
2019\end{array}$} & \multicolumn{16}{|c|}{ Years } \\
\hline & & \multirow{2}{*}{ Regional } & \multirow{2}{*}{$1990 \mathrm{~s}$} & \multirow{2}{*}{$2000 \mathrm{~s}$} & \multirow{2}{*}{2008} & \multirow{2}{*}{2009} & \multirow{2}{*}{2010} & \multirow{2}{*}{2011} & \multirow{2}{*}{2012} & \multirow{2}{*}{2013} & \multirow{2}{*}{2014} & \multirow{2}{*}{2015} & \multirow{2}{*}{2016} & \multirow{2}{*}{2017} & \multirow{2}{*}{2018} & \multirow{2}{*}{2019} & \multirow{2}{*}{2020} \\
\hline Arab World & 5.2 & & & & & & & & & & & & & & & & \\
\hline $\begin{array}{c}\text { East Asia \& Pacific } \\
\text { Euro area }\end{array}$ & $\begin{array}{c}6.6 \\
10.13\end{array}$ & Egypt & 5.1 & 4.6 & 4.6 & 4.3 & 4.5 & 4.9 & 4.5 & 4.0 & 4.1 & 5.1 & 4.6 & 5.6 & 4.9 & & \\
\hline European Union & 9.5 & & & & & & & & & & & & & & & & \\
\hline $\begin{array}{c}\text { Europe \& Central } \\
\text { Asia }\end{array}$ & 9.2 & Iraq & .. & 3.0 & 3.7 & 3.3 & 2.8 & 3.1 & 3.1 & 3.3 & 3.3 & .. & 3.0 & 4.1 & 4.1 & & \\
\hline $\begin{array}{c}\text { Latin America \& } \\
\text { Caribbean }\end{array}$ & 7.9 & Jordan & 9.6 & 8.7 & 9.5 & 8.0 & 8.3 & 7.9 & 7.3 & 7.4 & 6.2 & 9.6 & 8.7 & 8.1 & 7.7 & & \\
\hline $\begin{array}{l}\text { Least developed } \\
\text { countries: UN } \\
\text { classification }\end{array}$ & 4.0 & Kuwait & 2.5 & 1.9 & 3.8 & 2.7 & 2.6 & 2.5 & 2.5 & 3.1 & 4.0 & 2.5 & 1.9 & 5.2 & 4.9 & & \\
\hline $\begin{array}{c}\text { Middle East \& North } \\
\text { Africa }\end{array}$ & 5.9 & Oman & 3.0 & 2.0 & 2.8 & 2.7 & 2.5 & 2.5 & 2.8 & 3.4 & 3.8 & 3.0 & 2.0 & 3.9 & 4.1 & & \\
\hline OECD members & 12.45 & Qatar & 2.0 & 1.6 & 2.1 & 1.7 & 1.5 & 1.7 & 2.0 & 2.4 & 3.0 & 2.0 & 1.6 & 2.7 & 2.4 & & \\
\hline South Asia & 3.48 & $\begin{array}{l}\text { Saudi } \\
\text { Arabia }\end{array}$ & 4.2 & 2.8 & 4.0 & 3.4 & 3.6 & 3.9 & 4.3 & 5.0 & 5.8 & 4.2 & 2.8 & 7.0 & 6.3 & & \\
\hline Sub-Saharan Africa & 5.08 & Yemen Rep. & 4.1 & 5.1 & 5.3 & 5.1 & 5.0 & 5.7 & 5.7 & 5.6 & 5.9 & 4.1 & 5.1 & - & - & & \\
\hline World & 9.84 & & & & & & & & & & & & & & & & \\
\hline
\end{tabular}

Source: World Bank, 2020 


\subsection{Measuring Allocative Efficiency}

The conventional approach of measuring allocative efficiency is based on input costs, which is seldom recognized at the health care system level, but rather the total health expenditures. This paper proposes an unused approach of reallocation of health resources (Inputs) to measure allocative efficiency which is not based on the output-oriented distance to the production possibility curve in a profit and without the need for information on input prices [11]. To prove the unused approach, the researcher put a few genuine (literally approved) estimates so that allocative efficiency is achieved when decongestion of mal-distribution of resources or resources are reallocated in a way so as to maximize the welfare of the populace cohort. Certainly, this would happen when the extent of marginal benefits to marginal costs is break-even across all health systems. Neither marginal cost nor average cost information is accessible to ease the measurement, the researcher utilized the role of thump and focus on the estimates profiting from the productively efficient healthcare system to ensure the equitable dispersion of the outcomes among the Jordanian communities. The major portion of allocative efficacy in the Jordanian health care system that it comprises of a blend of duplicated and fragmented five primary providers to around 10 million populations. The duplicated curative and primary services was assessed by $25 \%$ of the share of spending across over the public, private and teaching hospitals [4]. Had this share been spared and redistributed basically based on the need and demand of the population, they would have saved more services; increased coverage and access to health services, reduced costs; so that making better-off people without harming anybody else [15].

The minor portion of allocative efficiency, On the other hand, is that the spending of almost $70 \%$ of total health expenditures on curative care and $30 \%$ over preventive care could be a clear sign of investing in less cost-effective services, subsequently, most of the health problems are preventable illnesses. Had the policy makers acknowledged this issue, by learning lessons from the disastrous pandemic COVID-19, by spending equally on preventive and curative measures, they would have had spare and saved more resources to gravelly required services. Also, this would increase coverage and improve equity. So, allocative efficiency is by one cruel or another not appear $[1,15]$.

\subsection{Measurement of Social Efficiency}

Social efficiency represents the capacity of the health system to guarantee unbiased get to quality health services at no monetary risk to clients. It contemplates the dispersal of output (reallocation of resources to make one individual better off without making at least one other individual worse off) [11].
In countries with unequal distribution of income, it is not conceivable to improve the conditions of the poor without expanding tax collection from the wealthy (equity). Social efficiency occurs if the total benefit to the gainers outweighs the total loss of the losers [15]. This paper accepts the equitable coverage of health services to the overall population as the suitable measure of social efficiency at no financial risk to users [16].

Currently, one of the exceptional key indicators of the health services coverage, approximately $70 \%$ of the population are publicly insured population by movement employees (with their dependents), and one third those who are not but are able to pay privately constitute $24 \%$ (two-third of them have private insurance), and the poor, apparently able to pay nothing are 6\%). Dissimilar to the industrial world, medical insurance coverage in Jordan has been growing rapidly since the 1990s. This state of the scope by insurance energized most of the population to utilize the health system without any financial burden, similarly to the poor (6\%). As a result, the larger part of the populace has clear access to health services in Jordan in spite of the geographical distribution, as preventive and curative measures are equitably scattered across the nation. In this case, the Jordanian health care system is considered to be socially efficient while maintaining other affected factors are equal (ceteris paribus) [12].

\subsection{Measurement of Horizontal Efficiency}

Horizontal efficiency can be defined as the proportion of those needing the health services who really get them. As in figure (1), - Horizontal efficacy = D/B.

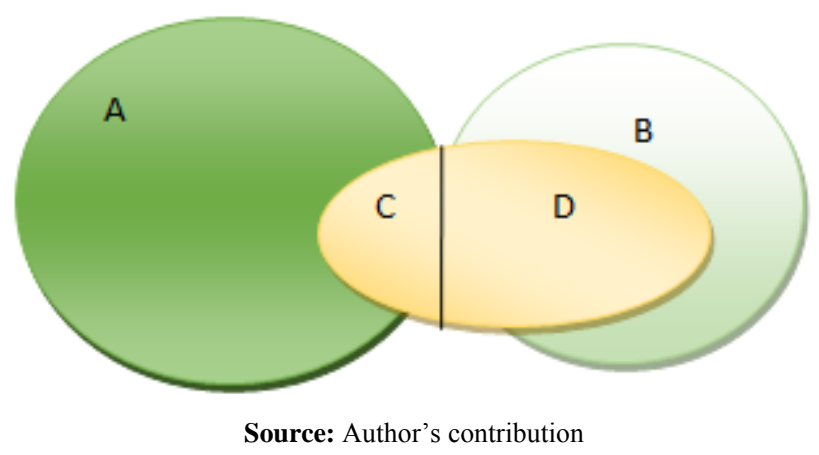

Figure 1. Distribution of health services across population

Horizontal efficiency refers to the ability of the Jordanian health care system proceeded to expand the scope of health services among the restrain of monetary assets and infrastructure, high cost of services, inefficiencies inside the current health system i.e. trades-off, decongestion of preventable demand (particularly with those who are insured and of those who have double insurance from the public sector, $(\mathrm{C}$ part in figure 1-abusers) will certainly influence the mode of delivery as well as the quality and efficiency of the health system. There were no imperial studies or other 
implications coupled with a lack of information to recognize the non-needy and trade-offs to facilitate in selectivity and prioritization of health services to the full populace in a horizontally efficient manner $[5,6,17]$.

\subsection{Measurement of Vertical Efficiency $(D /(D+C)$}

Vertical efficiency refers to the extent of services that be present at those who need them rather than to those that don't $[6,11]$, which represented by the $(C \& D)$ oval shape in diagram 1; and, could be measured by $\mathrm{D} /(\mathrm{D}+\mathrm{C})$. The previous (enumerator) (D) could be assessed by calculating the number of patient days in addition to the number of visits to health services per year, benchmarking a trend of ten years back, and expecting a long time in like manner. While the later $(\mathrm{C})$ is exceptionally troublesome to discover out since of lack of information. Therefore, solving the formula of $\mathrm{D} /(\mathrm{D}+\mathrm{C})$ is not possible. As far as the overall population (horizontal efficiency) which represents the major portion of the equation, parallel with a minimal number of abusers (C), this would yield slightly vertical efficiency of the health system, if compared with horizontal efficiency.

\section{Discussions}

The efficient health care delivery and financing systems are a worldwide issue of concern in the twenty-first century. Almost, about $25 \%$ of health expenditures in Jordan found to be a waste of scarce productive resources which is similar to the global wastage global trend of $20-40 \%$.

Efficiency, effectiveness, as well as equity, are essential supports to a quality healthcare system. Progressing efficiency in the health system can diminish the rising cost; provide equitable services to the needy to achieve the national strategic objective of health for all Jordanian in 2025; and viably prioritize healthcare services for foremost penniless by adjusting the trade-offs between efficiency, effectiveness, and equity [15]. Henceforth, prioritizing among accessible choices (70\% curative and $30 \%$ preventive) ought to be based on health problems, social and financial factors because of demand on healthcare assets are prominent than the accessible assets. Unequivocally, addressing priority setting is vital to create more efficient strategies of allocation for scarce productive health resources $[5,18]$.

Trade-offs which primarily founded in vertical efficiency compelled the wastage parcel within the health system (25\%), maybe overseen moving the oval shape in Figure:(1) (uncertain percentage) to the proper side- fixe in range (B)- to guarantee $100 \%$ vertical efficiency or that all of the needy have gotten the health services, with negligible penniless $(\mathrm{C})$ received. This may well be done by energizing and atomizing the delivery system which will help in curtailing the double insurance holders from the public sector, limiting extortion and embezzlement to health assists by great stewardship, and reduce the reciprocal services between health experts and others. In addition to the reestablishment of the targets of the health care delivery and financing systems. The health policymakers in Jordan have to pay a parcel of consideration to the trade-offs; as a poorly supported sub-health system, it's completely diverse motivation packages to improve vertical and horizontal efficiency of the health system or indeed bundles of prosperity establishments to the overall populace.

\section{Conclusions}

Bringing together, introduction and application of efficiency, effectiveness, and equity concepts to health systems are quite difficult and challenging and raising both theoretical and concrete problems. The next of kin between inputs and outcomes is multifaceted, driven by factors outside the control of health system managers.

This paper realizes and acknowledges practically applicable six sorts of efficiency that could be used and measured in health systems, suggesting everywhere the maximization of outputs for a given level of inputs or minimization of inputs for a given level of outputs (health outcome and/or health status) indicators i.e., life expectancy, IMR, MMR, CDR; while inputs may incorporate expenditure use on health care per se, physical inputs and environmental factors.

This paper finds approximately $25 \%$ of health expenditures in Jordan to be a waste of scarce productive resources which are comparable to the worldwide wastage trend of $20-40 \%$. In addition to that, $70 \%$ of the net share from the GNP goes to curative services and $30 \%$ goes for preventive services. This means that Jordan spends on less cost-effective measures.

Progressing efficiency within the health system can reduce the rising cost; provide equitable services to the penniless to attain the national key objective of health for all Jordanians in 2025, and reasonably prioritizing healthcare services for the first penniless by adjusting the trade-offs. From now on, prioritizing among available choices ( $70 \%$ curative and $30 \%$ preventive) ought to be based on health problems, social and financial related components since of demand for healthcare resources is more noticeable than the accessible resources. Unequivocally, addressing priority setting is imperative to make more efficient strategies of allocation for scarce productive health resources.

Despite the remarkable specific types of efficiency i.e., productive capabilities of the Jordanian health care system founded, the paper recommended a thoroughly enforced reform strategy to attain the national key objective (health for all in Y2025). 
Jordan as a country of limited resources for healthcare, a combination of neglected health needs, and compliance with directives orders recommended paying consideration to tradeoffs in production unction and utilization in the overall health system. Introducing efficiency into healthcare delivery with a full understanding of its typology can offer room for progressing adequacy and value in healthcare as prove by the discoveries in this article i.e., avoidable wastages and inefficiency in production and utilization of health care.

As for efficiency as the managerial apparatus is exceptionally difficult to apply in health fields due to the complexity of the system, the article could be utilized as a base for future studies to join more wide zones of comparisons i.e., developed states to pinpoint the gaps between countries of comparable and non-similar characteristics and provide selective solutions to bridging these gaps.

\section{Acknowledgements}

This paper would not have been conceivable without the extraordinary back of my colleagues. Professor Mohammed Al-Wedian in Jordan University of Science and Technology Professor Anis Khassawneh in Yarmouk University. Their eagerness, information, and demanding consideration to detail of debatable efficiency in the workforce in faculty of engineering and faculty of public administration have been a motivation to start up and kept my work on the way.

All data created and used in this study are openly available in the World Bank and Ministry of Health of Jordan annual reports.

I, therefore, certify that there's no conflict of interest associated with this application, and there has been no financial support for this work that might have an impact on its outcomes.

\section{REFERENCES}

[1] Peacock, S., Chan, C., Mangolini, M. and Johansen, D, "Techniques for Measuring Efficiency in Health Services", Productivity Commission Staff Working Paper, Commonwealth of Australia: Productivity Commission. 2001.https://www.pc.gov.au/research/supporting/measurin g-health-services/tmeihs.pdf. Accessed April 19, 2021.

[2] Enrique Burches, and Marta Burche, "Efficacy, Effectiveness and Efficiency in the Health Care: The Need for an Agreement to Clarify its Meaning", International Archives of Public Health and Community Medicine, 4(1), pp.1-3. 2020.

[3] Bruce Hollingsworth, "The measurement of efficiency and productivity of health care delivery", Health Economics, 17 (10), pp. 1107-28, 2008.
[4] Rawabdeh, A.; Rami M. Tbaishat; Ahmad Zakaria; and, Iman El Hajj Dib Zakaria, "Reforming Health Policy in Jordan: Finance and Allocating Public Expenditures: a Worldwide Review", Indian Journal of Science and Technology, 12(38), pp. 1-16, 2019

[5] Tao Yi, Kizito Henry, Qinpei Zou1 \& Xiaoni Zhong, "Methods for measuring horizontal equity in health resource allocation: a comparative study", Health Econ Rev. 4 (10), 2014, https://doi.org/10.1186/s13561-014-0010-x

[6] Marten Lagergren; Britt- Marie S. Cecilia F; Johan B. Laura F.; Eva N.; Lendrs W.; and, Solve E, "Horizontal and vertical target efficiency - a comparison between users and non-users of public long-term care in Sweden", Ageing \& Society, 34, (4), pp. $700-719,2016$.

[7] Jonathan Cylus, Irene Papanicolas and Peter C. Smith, "Health System Efficiency" How to make measurement matter for policy and management, Publications, WHO Regional Office for Europe: Denmark, 2016 https://www.euro.who.int/_data/assets/pdf_file/0004/324 283/Health-System-Efficiency-How-make-measurement-m atter-policy-management.pdf.

[8] Grech, Kenneth E, and Andrzej Ryś, "Tools and Methodologies to assess the Efficiency of Health Care Services in Europe", Health and Food Safety European Commission. An overview of current approaches and opportunities for improvement Report by the Expert Group on Health System Performance Assessment, 2019. https://ec.europa.eu/health/sites/default/files/systems_perfo rmance_assessment/docs/2019_efficiency_en.pdf.

[9] João Medeiros and Christoph Schwierz, "Efficiency estimates of health care systems in the EU", Luxembourg: Publications Office of the European Union, 2015. http://ec.europa.eu/economy_finance/publications.

Accessed April 23, 2021.10- OECD, "Scoping paper on health system efficiency measurement. cooperation between the OECD and EC in promoting efficiency in health care", 2016. https://www.oecd.org/health/health-sys tems/Scoping-Paper-Measuring-efficiency-in-health-syste m.pdf.

[10] OECD. Scoping paper on health system efficiency measurement.: cooperation between the OECD and EC in promoting efficiency in health care. 2016. https://www.oecd.org/health/health-systems/Scoping-Pape r-Measuring-efficiency-in-health-system.pdf.

[11] Ann Clawer and David Perkins, "Economics for Health Care Management", Prentice Hall: Simon \& Schuster International Group, London, 1998.

[12] $\mathrm{MOH}$, "Annual Statistical Report", Ministry of Health of Jordan, 2020. https://www.moh.gov.jo/Echobusv3.0/Syste mAssets/04c240a1-dcc8-4df9-bdda-eefca59ad4c3.pdf

[13] Peter S Hussey, Han de Vries, John Romley, Margaret C Wang, Susan S Chen, Paul G Shekelle, and Elizabeth A McGlynn, "A Systematic Review of Health Care Efficiency Measures", 44(3), pp. 784-805, 2009.

[14] Anton Leis Garcia; Nesreen Barakat Rani Khoury, and, Guillaume Lecaros de Cossio, "Compact for Economic Governance", Stocktaking Report: Jordan, OECD German Foreign Office, 2018, Compact-for-Governance-Stocktaki ng-Report-Jordan-2018-EN.pdf (oecd.org). 
[15] Mende Mensa Sorato, Akbar Abdollahi Asl and Majid Davari, "Improving Health Care System Efficiency for Equity, Quality and Access: Does the Healthcare Decision Making Involve the Concerns of Equity? Explanatory Review", J Health Med Econ, 6 (1), pp. 45, 2020

[16] Behr Andreas and Theune Katja, "Health System Efficiency: A Fragmented Picture Based on OECD Data", Pharmacoecon Open, 1(3), pp. 203-221. 2017.
[17] Patrick M. Bernet, James Moises, Vivian Grace Valdmanis, "Social Efficiency of Hospital Care Delivery: Frontier Analysis from the Consumer's Perspective", Medical Care Research and Review, 68 (1), pp. 36S-54S, 2010.

[18] Juan Fernando Matajudios Carmona, Cristian Fernán Muñoz Muñoz, "Diagnosis and Intervention Program for Burnout Syndrome in Primary and Secondary Teachers at a School in Pereira", Universal Journal of Public Health Vol. 9(2), pp. 75 - 82, 2021. DOI: 10.13189/ujph.2021.090206 